\title{
Efficiency of enuresis prevention for 7-year-old children first entering school in the Russian Federation
}

\author{
Kirill Kosilov $^{1}$, Sergey Loparev ${ }^{2}$, Irina Kuzina ${ }^{3}$, Olga Shakirova ${ }^{3}$, Nataliya Zhuravskaya ${ }^{3}$, Alexandra \\ Lobodenko ${ }^{3}$
}

Sri Lanka Journal of Child Health, 2017; 46: 33-38

\begin{abstract}
Objective: To study the efficiency of enuresis prevention for 7-year-old children first entering school and having no experience of staying in preschool institutions.
\end{abstract}

Method: The following groups among 7-year-old children (mean age $7.2 \pm 0.6$ years) who had a planned prophylactic medical examination were formed by means of random sampling: Group A included children diagnosed with primary monosymptomatic enuresis (PMNE) at the age of 5-7 years, but in whom at the time of admission to school, sleep urinations were not observed. This group had alarm intervention as a prophylactic measure. Group B similarly included children who diagnosed with PMNE at the age of 5-7 years, and in whom at the time of admission to school, sleep urinations were not observed. However, in this group there was no alarm intervention. Group $\mathrm{C}$ included children in whom after the age of 5 years no episodes of sleep urination were observed. According to the recommendations of International Children's Continence Society (ICCS), enuresis was established in the event of at least two episodes of urinary incontinence per week and the duration of symptoms was at least 3 months. All these children were admitted to the first class of secondary school one month after the beginning of observation. Patients of all three groups were laboratory tested and had uroflowmetry and questionnaire survey with OAB-q SF. The study design was approved by the Ethics Committee of the Far Eastern Federal University.

Results: Mean number of dry nights was markedly less in group B $(4.5 \pm 0.7)$ compared to groups A $(6.2 \pm 0.8)$ and $C(6.6 \pm 0.8)$. This was statistically

${ }^{1}$ Far Eastern Federal University, ${ }^{2}$ Department of Urology, City Polyclinic No. 3, ${ }^{3}$ Far Eastern Federal University, Russian Federation

*Correspondence: oton2000@mail.ru

(Received on 21 February 2016: Accepted after revision on 11 May 2016)

The authors declare that there are no conflicts of interest

Personal funding was used in formulating the article.

Open Access Article published under the Creative

Commons Attribution CC-BY License. significant $(\mathrm{p}<0.05)$. Mean number of enuresis episodes significantly increased in both groups A $(\mathrm{p}<0.05)$ and $\mathrm{B}(\mathrm{p}<0.01)$ compared to group $\mathrm{C}$ at 1 month. However, at 3 months significant differences remained only for group B $(p<0.05)$ compared to group $\mathrm{C}$. The percentage of children having at least two episodes of enuresis per week for 3 months was $21.8 \%$ in group B compared with $5.7 \%$ in group $\mathrm{C}(\mathrm{p}<0.05)$ and $6.8 \%$ in group $\mathrm{A}$.

Conclusions: In this study, children without PMNE had a low risk of developing enuresis on school admission. In children with PMNE at the age of 5-7 years, who successfully overcame it and had no prophylactic alarm intervention, risk of developing enuresis on school admission was significantly higher than in children without PMNE. In children with PMNE at 5-7 years of age, who successfully overcame it and who had prophylactic alarm intervention, risk of developing enuresis on school admission did not differ significantly from that in children without PMNE.

DOI: http://dx.doi.org/10.4038/sljch.v46i1.8075

(Key words: Enuresis, alarm therapy, children, school)

\section{Introduction}

Prevalence of primary monosymptomatic night enuresis (PMNE) is $1.6 \%^{1}, 5.3 \%^{2}, 15 \%^{3}, 18.7 \%^{4}$ and $28.6 \% 5$ respectively according to different sources. It is known that prevalence of monosymptomatic night enuresis (MNE) is conditioned by factors such as gender, heredity, peculiarities of family relations and economic strength of families ${ }^{6,7}$. Not all authors of scientific periodicals represented in Scopus, MedLine, PubMed, Web of Science databases adhere to the recommendations of International Children's Continence Society (ICCS) and National Clinical Guideline Centre, UK (NCGC) $)^{8,9}$ and, therefore, obtain results parts of which are difficult to compare with other studies ${ }^{10,11}$. Besides, it is common knowledge that the percentage of children with problems of night urinary bladder emptying correlates with age ${ }^{5,12}$, though some studies do not confirm it ${ }^{6}$. Psycho-emotional stress, excessive psychological and physical exertion ${ }^{13-16}$ connected among others with child's admission to school are often mentioned as reasons for the risk of loss of 
control over urination during sleep ${ }^{17-19}$. It is known that such exertions can result in functional deterioration of sympathetic nervous system activity and disruption of circadian rhythm of sleep-wakefulness cycle, which are risk factors for enuresis development ${ }^{20,21}$.

\section{Objective}

To study the efficiency of enuresis prevention for 7-year-old children first entering school and having no experience of staying in preschool institutions.

\section{Method}

The study was carried out from June 1 to November 30, 2014 in the Urologic Centre of Vladivostok Polyclinic No. 3. Before being enrolled in the initial (first) form of school, all children underwent a planned medical examination 3-4 months before the start of classes. In accordance with the study protocol, we formed 3 groups. Group A included children diagnosed with primary monosymptomatic enuresis (PMNE) at the age of 5-7 years, but in whom at the time of admission to school, sleep urinations were not observed. This group had alarm intervention as a prophylactic measure. Group B similarly included children who diagnosed with PMNE at the age of 5-7 years, and in whom at the time of admission to school, sleep urinations were not observed. However, in this group there was no alarm intervention. Group C included children in whom after the age of 5 years no episodes of sleep urination were observed (control group). All 3 groups included children who sought medical advice from a local paediatrician on odd-numbered days of the week. To ensure a random allocation into groups $\mathrm{A}$ and $\mathrm{B}$ stratified (layered) randomization was used, ensuring equal gender representation in groups. The allocation was carried out randomly, in accordance with assigned numbers received using a random number generator. The confidence level of $95 \%$ (a range of $\pm 5 \%$ ) was determined calculating the sample size. Secondary allocation concealment (after the end of the follow-up) was ensured by anonymization of patients' medical cards before enrolling in a group at the start of the experiment. Demographic characteristics of groups are presented in Table 1.

Table 1: Demographic characteristics of examined children $(n=364)$

\begin{tabular}{|l|c|c|c|}
\hline Demographic characteristic & Group A (n=118) & Group B (n=124) & Group C (n=122) \\
\hline Average age & $7.1 \pm 0.3$ & $7.3 \pm 0.5$ & $7.3 \pm 0.3$ \\
\hline Gender & $67(57 \%)$ & $72(58 \%)$ & $81(66 \%)$ \\
Male & $51(43 \%)$ & $52(42 \%)$ & $41(34 \%)$ \\
Female & $89(75 \%)$ & $102(82 \%)$ & $83(68 \%)$ \\
\hline Full family & $0.9(0.2)$ & $1.0(0.4)$ & $0.7(0.2)$ \\
\hline Sibling & \multicolumn{2}{|}{} \\
\hline
\end{tabular}

According to the ICCS recommendations, enuresis was established in the event of at least two episodes of urinary incontinence per week for at least 3 months. Information about urination in sleep at the age of 5-7-years that later spontaneously stopped was collected through parental questioning and analysis of paediatrician records in individual medical cards. A personal polyclinic medical card is a document of medical reporting that contains the column "Sheet of revised diagnoses". The availability of PMNE history diagnosed in accordance with the ICCS recommendations was a criterion for inclusion of patients in group A or B. The absence of documentary evidence of PMNE diagnosis (absence in a personal medical card of data of voiding diaries, uroflowmetry, and antidiuretic hormone blood test) was an exclusion criterion. Other exclusion criteria were the presence of a neurological disorder, overactive bladder or diabetes.

All these children were admitted to the first class of secondary school one month after the beginning of observation. All three groups of children were laboratory tested (white blood cell count and differential count, analysis of level of antidiuretic hormone, urine analysis, stool test), and had uroflowmetry $^{22}$ and survey of parents of children by questionnaire OAB-q $\mathrm{SF}^{23}$. The questionnaire was filled in by parents or guardians of the children. Then, according to study protocol, the parents of the children filled in the urination diaries over the period of three months of observation ${ }^{24}$, recording information about frequency and volume of urination in daytime and nighttime, about episodes of urination in sleep, self-awakenings in case of desire to urinate and number of dry nights.

Children in group A had alarm intervention with the aid of the alarm system Wet Stop/ BYE-WET by PALCO LABS, Inc (USA) in standard configuration over the period of 3 months. The stages of this study protocol are represented in Figure 1. 


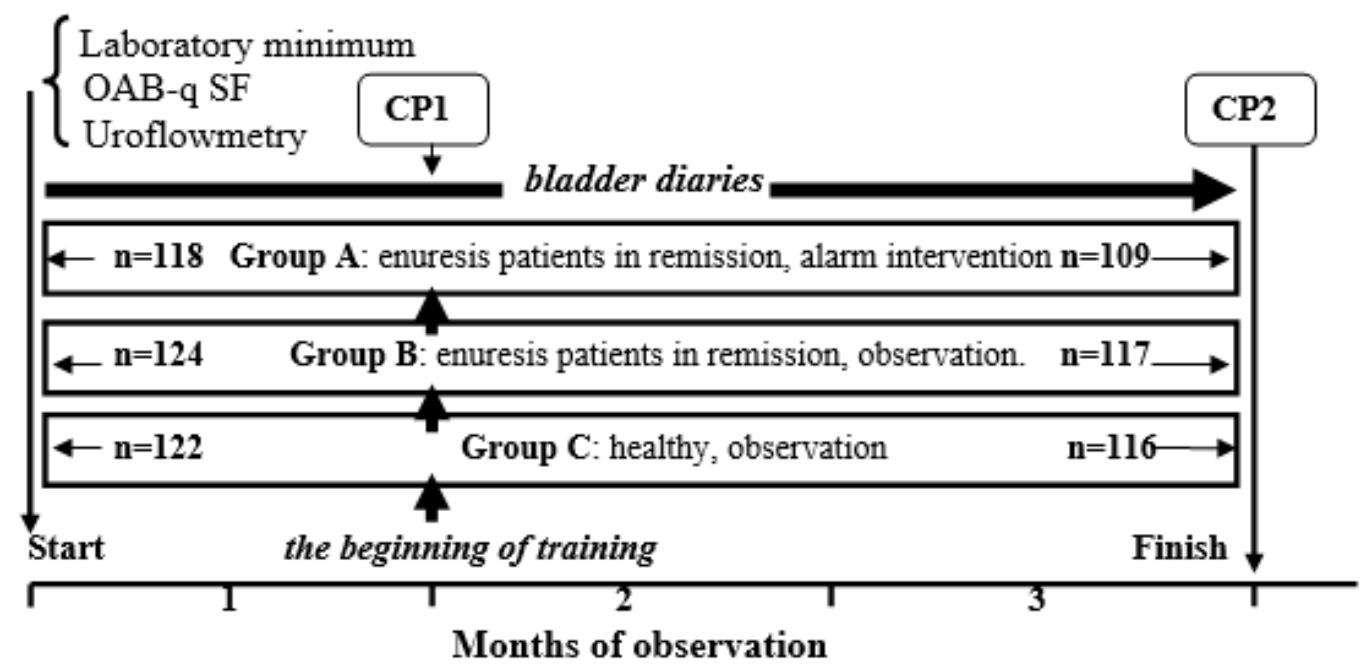

Figure 1: Scheme of examination, observation and treatment of patients with enuresis

\section{$C P$ - control point; $O A B-q S F$ - overactive bladder questionnaire}

Results obtained were processed and analysed using JMP SAS Statistical Discovery 8.0.2 (SAS Institute, Cary, NC, USA). Wilcoxon test was used for comparison of data sampling. Comparison of dynamics of change was carried out with the help of Spearman index. $\mathrm{P}$ value $<0.05$ was considered significant.The study was approved by the Ethics Committee of the Far Eastern Federal University.

\section{Results}

Questioning with the help of questionnaire OAB-q allowed us to determine that the average score was $3.7 \pm 0.9$. Analysis of uroflometry data allowed us to determine that the median value of urine maximum volumetric flow rate $\left(\mathrm{Q}_{\max }\right)$ for the group was 18.5 (4.2) $\mathrm{ml} / \mathrm{second}$, average velocity of urination $\left(\mathrm{Q}_{\mathrm{mid}}\right)$ was 15 (3.9) $\mathrm{ml} /$ second, average urination volume $(\mathrm{V})$ was $251.2(57.0) \mathrm{ml}$ and the average time taken to reach maximum velocity $\left(T Q_{\max }\right)$ was 5.1 (1.1) seconds. The level of antidiuretic hormone in each case of examination corresponded to standard values at the level of osmolarity that was set for the patient. Blood and urine tests did not reveal any abnormal changes.

Table 2 represents data of change in enuresis markers over the whole period of observation.

Table 2: Change in markers of enuresis during the experiment

\begin{tabular}{|c|c|c|c|c|c|c|c|c|c|}
\hline & \multicolumn{3}{|c|}{$\begin{array}{l}\text { Mean ( } \pm \text { SD) number of } \\
\text { "dry" nights per week }\end{array}$} & \multicolumn{3}{|c|}{$\begin{array}{c}\text { Mean ( } \pm \text { SD) episodes of } \\
\text { enuresis per week }\end{array}$} & \multicolumn{3}{|c|}{$\begin{array}{c}\text { Mean ( } \pm \text { SD) number of } \\
\text { self-awakenings per week }\end{array}$} \\
\hline $\begin{array}{c}\text { Monitoring } \\
\text { period }\end{array}$ & start & CP1 & CP2 & start & CP1 & CP2 & start & CP1 & CP2 \\
\hline $\begin{array}{c}\text { Group A } \\
n=118 \\
\end{array}$ & $\begin{array}{c}6.4 \\
(1.2) \\
\end{array}$ & $\begin{array}{c}6.0 \\
(1.7) \\
\end{array}$ & $\begin{array}{c}6.2 \\
(0.8) \\
\end{array}$ & $\begin{array}{c}0.7 \\
(0.3) \\
\end{array}$ & $\begin{array}{c}1.7 \\
(0.5)^{*}\end{array}$ & $\begin{array}{c}0.9 \\
(0.3) \\
\end{array}$ & $\begin{array}{c}1.4 \\
(0.4) \\
\end{array}$ & $\begin{array}{c}1.9 \\
(0.8) \\
\end{array}$ & $\begin{array}{c}2.6 \\
(0.7)^{*}\end{array}$ \\
\hline $\begin{array}{c}\text { Group B } \\
\mathbf{n}=124\end{array}$ & $\begin{array}{c}6.3 \\
(0.7) \\
\end{array}$ & $\begin{array}{c}4.8 \\
(0.6)^{*} \\
\end{array}$ & $\begin{array}{c}4.5 \\
(0.7)^{*} \\
\end{array}$ & $\begin{array}{c}0.8 \\
(0.2) \\
\end{array}$ & $\begin{array}{c}2.0 \\
(0.5)^{* *}\end{array}$ & $\begin{array}{c}2.1 \\
(0.7)^{*}\end{array}$ & $\begin{array}{c}1.8 \\
(0.5) \\
\end{array}$ & $\begin{array}{c}1.0 \\
(0.5) \\
\end{array}$ & $\begin{array}{c}0.5 \\
(0.6)^{*} \\
\end{array}$ \\
\hline $\begin{array}{c}\text { Group C } \\
\mathbf{n}=122\end{array}$ & $\begin{array}{c}6.8 \\
(1.1)\end{array}$ & $\begin{array}{c}6.1 \\
(0.6)\end{array}$ & $\begin{array}{c}6.6 \\
(0.8) \\
\end{array}$ & $\begin{array}{c}0.2 \\
(0.2)\end{array}$ & $\begin{array}{c}0.4 \\
(0.3) \\
\end{array}$ & $\begin{array}{c}0.1 \\
(0.2)\end{array}$ & $\begin{array}{c}2.1 \\
(0.9)\end{array}$ & $\begin{array}{c}2.5 \\
(0.4)\end{array}$ & $\begin{array}{c}2.5 \\
(0.8) \\
\end{array}$ \\
\hline
\end{tabular}

The significance of differences $* p<0.05 ; * * p<0.01$. The table shows the significance of the differences between the results on start of observation vs the results 1 and 3 month after the start of the study. CP-control point 1, 2.

Mean number of dry nights reliably decreased in group B, while in other two groups there was hardly any change. Comparison of this parameter at the first study control point (CP1) showed significant differences between groups $\mathrm{B}$ and $\mathrm{C}$ $(p<0.05)$. At the final control point $(\mathrm{CP} 2)$ the parameter values in group $\mathrm{B}$ were significantly different from those in groups $\mathrm{A}$ and $\mathrm{C}(\mathrm{p}<0.05)$. 
Mean value of enuresis episodes at the first study endpoint (CP1) significantly increased in both groups $A(p<0.05)$ and $B(p<0.01)$ compared to group C. However, at the final control point (CP2) significant differences remained only for group $\mathrm{B}$ $(\mathrm{p}<0.05)$ compared to group $\mathrm{C}$.

Number of self-awakenings in all 3 groups after the beginning of lessons reliably stayed unchanged. At the second endpoint (CP2) the changes in groups A and $\mathrm{B}$ were in opposite directions. In group $\mathrm{A}$ the average value of the parameter significantly increased $(p<0.05)$. In group $B$, on the contrary, it significantly decreased $(\mathrm{p}<0.05)$. At the first endpoint (CP1) the parameter value was reliably different in groups $\mathrm{B}$ and $\mathrm{C}$. In the course of comparison of values at the second endpoint (CP2) the mean values of frequency of self-awakenings in groups $\mathrm{A}$ and $\mathrm{C}$ proved to be almost the same, and differed markedly from the values of this parameter in group $B(p<0.01)$. Correlation between the lines reflecting dynamics of values of dry nights and enuresis episodes in all groups was within the average values $(\mathrm{r}=0.51-0.69, \mathrm{p}<0.05)$. Correlation of dynamics of frequency of self-awakenings in groups $\mathrm{A}$ and $\mathrm{B}$ comprised $\mathrm{r}=0.32, \mathrm{p}<0.05$.

Figure 2 represents change of percentage of patients who have more than 2 episodes of urination in sleep per week at the beginning of study, one week after beginning of the lessons and 2 months after beginning of the lessons.

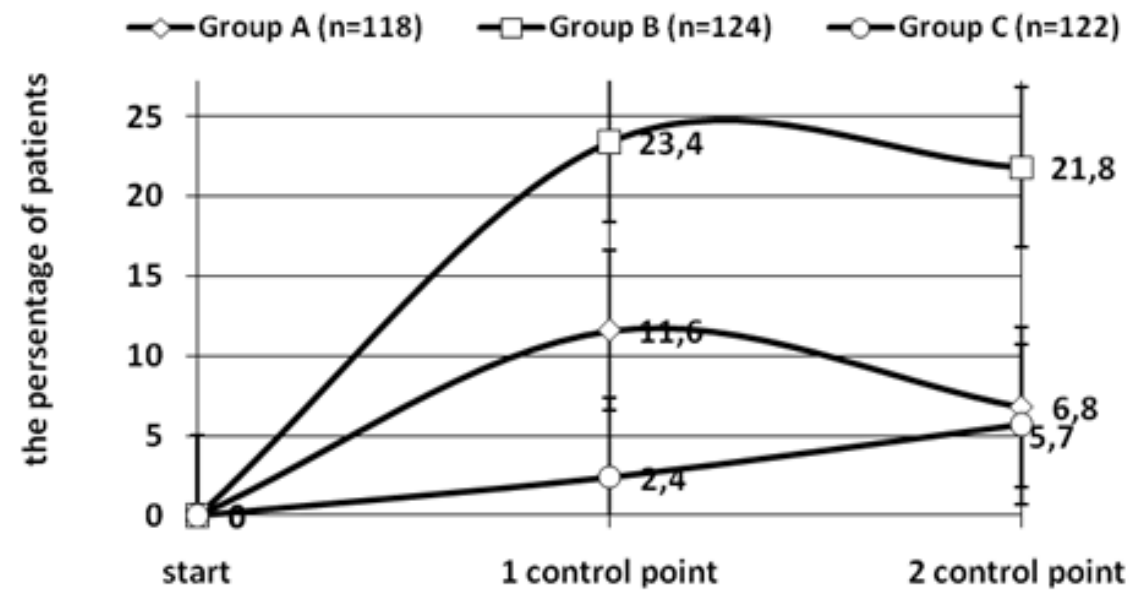

Figure 2: Percentage of patients with episodes of enuresis more than 2 per week

Comparison of the results at the first endpoint allowed detecting reliable differences between the percentages of such patients in control group (2.4 percent), in the group of persons who used to suffer from enuresis and had alarm therapy (11.6 percent), and their counterparts who had no treatment $(23.4$ percent). At the final endpoint it was detected that number of children with more than two episodes of urination in sleep in groups $\mathrm{A}$ and $\mathrm{C}$ were almost the same and did not differ significantly from initial value $(\mathrm{p}>0.05)$. By contrast, percentage of such children in group B was still high after two months and significantly differed both from initial value and from the results in groups $\mathrm{A}$ and $\mathrm{C}$.

Nineteen (5.2 percent) children were withdrawn from the study. Among them 14 parents failed to fill in the urination diaries (4 each from groups A and C, 6 from group B), 2 parents withdrew their children due to negative attitude to usage of alarm system, 1 parent due to child having an acute respiratory infection and 2 parents without explanation of the reasons.

\section{Discussion}

It was determined during the study that children without PMNE (Group C) have a low risk of developing enuresis symptoms despite significant psychological and physical exertions connected with admission to school. The percentage of healthy children who had urination in sleep after beginning of lessons was statistically insignificant. In contrast, among children suffering from PMNE at the age of 5-7, but who successfully overcame it, the risk of return of such pathology was rather high, $23.4 \%$ such children having episodes of urination in sleep again under the influence of stresses connected with the beginning of study at school. Moreover, 21.8\% still had episodes of urination in sleep even 2 months after beginning of lessons i.e. after relative adaptation of child to new external conditions. In case of preventive use of one of the first-line methods of enuresis treatment 
recommended by ICCS viz. alarm intervention, the risk of disease return reduced, $11.6 \%$ of children recording more than two episodes of bed urinations per week right after the beginning of lessons, and $6.8 \%$ of children after two months of going to school but this was not statistically significant.

In our opinion, one possible explanation of such a result can be sleep structural damage under the influence of stress factors on the child, which is reported in the literature ${ }^{25-27}$. ICCS in its recommendations mentions sleep disturbance as one of the possible mechanisms of enuresis formation $^{28}$. Excessive fatigability against the background of psychic and physical exertions, probably, results in disturbance of functional activity of reticular formation, and usual afferent stream in case of bladder overflow cannot call wakening anymore. If we increase the stream of afferent impulses at the expense of alarm system actuating, it becomes sufficient for wakening.

Indeed, we do not consider the results obtained and their interpretation exhaustible, and adhere to necessity of study continuation. In particular, in our opinion, the problem of possible positive effect of preparatory school courses, which adapt children to stress of the first weeks of education, remains open and, probably, casts some doubt on advisability of preventive treatment of enuresis. We also consider it necessary to study efficiency of short course of antidiuretic hormone as the measure of preventive treatment and some other directions.

\section{Conclusions}

- In this study, children without PMNE had a low risk of developing enuresis on school admission.

- In children with PMNE at the age of 5-7 years, but who successfully overcame it and who had no alarm intervention prophylactically, the risk of developing enuresis on school admission was significantly higher than in children without PMNE.

- In children with PMNE at the age of 5-7 years, but who successfully overcame it and who had alarm intervention prophylactically, the risk of developing enuresis on school admission was not significantly different from that in children without PMNE.

\section{References}

1. Esposito M, Gallai B, Parisi L et al. Primary nocturnal enuresis as a risk factor for sleep disorders: an observational questionnaire-based multicenter study. Neuropsychiatric Disease and Treatment 2013; 9:437-43.

2. Merhi BA, Hammoud A, Ziade F, et al. Mono-symptomatic nocturnal enuresis in Lebanese children: prevalence, relation with obesity, and psychological effect. Clinical Medical Insights. Pediatrics 2014; 8:5-9.

3. Yazici CM, Abali R, Tasdemir N. et al. Is nocturia of young adulthood a remnant of childhood nocturnal enuresis? International Urogynecology Journal. 2014; 25(2):273-8.

4. Hashem M, Morteza A, Mohammad K. Prevalence of nocturnal enuresis in school aged children: the role of personal and parents related socio-economic and educational factors. Iranian Journal of Pediatrics 2013; 23(1):59-64.

5. Aljefri HM, Basurreh OA, Yunus F. et al. Nocturnal enuresis among primary school children. Saudi Journal of Kidney Diseases and Transplantation 2013; 24(6):1233-41.

6. Baek M, Park K, Lee $\mathrm{H}$ et al. A nationwide epidemiological study of nocturnal enuresis in Korean adolescents and adults: population based cross sectional study. Journal of Korean Medical Science 2013; 28(7):1065-70.

7. Dolgun G, Savaser S, Balci S. Prevalence of nocturnal enuresis and related factors in children aged 5-13 in Istanbul. Iranian Journal of Pediatrics 2012; 22(2):205-12.

8. Nocturnal enuresis: The management of bedwetting in children and young people. National Clinical Guideline Centre (UK). London: Royal College of Physicians (UK); 2010.

9. Bottomley G. Treating nocturnal enuresis in children in primary care. Practitioner 2011; 255(1741):23-6.

10. Deshpande AV, Caldwell PH. Medical management of nocturnal enuresis. Paediatric Drugs. 2012; 14(2):71-7. 
11. Otu-Bassey IB, Useh MF, Alaribe AA. The post-treatment effects of enterobiasis on the occurrence of enuresis among children in Calabar, Nigeria. Asian Pacific Journal of Tropical Medicine 2011; 4(4): 315-9.

12. Chang JW, Yang LY, Chin TW, et al. Clinical characteristics, nocturnal antidiuretic hormone levels, and responsiveness to DDAVP of school children with primary nocturnal enuresis. World Journal of Urology 2012; 30(4): 567-71.

13. von Gontard A. Does psychological stress affect LUT function in children? ICI-RS 2011. Neurourology and Urodynamics 2012; 31(3):344-8.

14. De Bruyne E, Van Hoecke E, Van Gompel K. Problem behaviour, parental stress and enuresis. Journal of Urology 2009; 182(4 Suppl):2015-20.

15. Baeyens D, Lierman A, Roeyers $H$, Adherence in children with nocturnal enuresis. Journal of Pediatric Urology 2009; 5(2):105-9.

16. Moro ET, Módolo NS. Children, parents and anxiety. Rev Bras Anestesiol. 2004; 54(5):728-38. [Article in Portuguese]

17. Azhir A, Frajzadegan Z, Adibi A et al. An epidemiological study of enuresis among primary school children in Isfahan, Iran. Saudi Medical Journal 2006; 27(10): 1572-7.

18. Russ S, Smith J, Landes C, et al. A team approach to enuresis and school reluctance. Journal of School Health 2005; 75(2):75-7.

19. Kumazawa-Ichikawa $\mathrm{MR}^{1}$, FrancoTostado B, Ruvalcaba-Aceves R. Management of primary nocturnal enuresis in school children with slow learning ability: usefulness of imipramine. Bol Med Hosp Infant Mex. 1990; 47(6):390-4. [Article in Spanish]

20. Pashapour N, Golmahammadlou S, Mahmoodzadeh H. Nocturnal enuresis and its treatment among primary school children in Oromieh, Islamic Republic of Iran. Eastern Mediterranean Health Journal 2008; 14(2): 376-80.

21. Dogan HS, Akpinar B, Gurocak $\mathrm{S}$ et al. Non-invasive evaluation of voiding function in asymptomatic primary school children. Pediatric Nephrology 2008; 23(7): 1115-22.

22. Gupta DK, Sankhwar SN, Goel A.Uroflowmetry nomograms for healthy children 5 to 15 years old. Journal of Urology 2013; 190(3):1008-13.

23. McKown S, Abraham L, Coyne $\mathrm{K}$ et al. Linguistic validation of the N-QOL (ICIQ), OAB-q (ICIQ), PPBC, OAB-S and ICIQ-MLUTSsex questionnaires in 16 languages. International Journal of Clinical Practice 2010; 64(12):1643-52.

24. Kwak KW, Park KH. Clinical inconsistency of lower urinary tract symptoms between questionnaire and bladder diary in children with nocturnal enuresis. Journal of Urology 2008; 180(3): 1085-9.

25. Lehmkuhl G, Fricke-Oerkermann L, Wiater A et al. Sleep disorders in children beginning school: their causes and effects. Dtsch Arztebl Int. 2008; 105(47):809-14.

26. O'Brien LM, Lucas NH, Felt BT et al. Aggressive behavior, bullying, snoring, and sleepiness in schoolchildren. Sleep Medicine 2011; 12(7):652-8.

27. Petry C, Pereira MU, Pitrez PM, et al. The prevalence of symptoms of sleepdisordered breathing in Brazilian schoolchildren. Journal of Pediatrics (Rio J). 2008; 84(2):123-9.

28. Johan Vande Walle, Soren Rittig, Stuart Bauer et al. Practical consensus guidelines for the management of_enuresis. European Journal of Pediatrics 2012; 171(6): 97183. 